\title{
Somehow They Are Never Horny!
}

Gopinaath Kannabiran Department of Computer Science, Aarhus University Aarhus, 8200, Denmark gopinaath@cs.au.dk

Eve Hoggan

Department of Computer

Science, Aarhus University

Aarhus, 8200, Denmark

eve.hoggan@cs.au.dk
Lone Koefoed Hansen

Department of Digital Design and

Information Studies, Aarhus

University

Aarhus, 8200, Denmark

koefoed@cavi.au.dk

\begin{abstract}
With this provocation, we argue that existing $\mathrm{HCl}$ discourses on ageing risk rendering older adults as asexual individuals through research writing. We begin by articulating how discursive subjectivities such as users, consumers, participants, etc. are constructed, maintained, and propagated as representations of other individuals/groups through $\mathrm{HCl}$ research. We build our argument with examples highlighting tropes that have led to marginalization of certain groups of individuals through research writing. Through our provocation, we argue for re-framing and exploring sexual wellbeing of older adults as a fundamental humans rights issue and social justice concern while designing technologies. We point to problematic assumptions, amplify concerns, and call for further $\mathrm{HCl}$ research on sexual needs, desires, and experiences of older adults.
\end{abstract}

\section{Author Keywords}

sexuality; older adults; gerontology; sexual wellbeing;

\section{CCS Concepts}

-Human-centered computing $\rightarrow$ Human computer interaction $(\mathrm{HCl})$; Human computer interaction $(\mathrm{HCl})$; Haptic devices; Human computer interaction $(\mathrm{HCl})$; Haptic devices; User studies; 


\section{Introduction}

"I rolled over on my side and saw that my husband of almost 40 years was grinning. "It's not supposed to be this good when you're this old." Radosh, [16].

Dr. Sidney Katz and his team developed ADL "to measure gains and losses in physical function and serve as the basis for making prognoses for patients treated at the hospital for strokes, hip fractures, and other disabling conditions" [15].

\section{Index of Independence}

Katz measured inde-

pendence in older adults based on six daily activities: bathing, dressing, toileting, transferring, continence, and feeding.

\section{Instrumental Activities of}

\section{Daily Living (IADL)}

Engaging with more complex everyday life activities, IADL focuses on eight functions: ability to use telephone, shopping, food preparation, housekeeping, laundry, mode of transportation, responsibility for own medicines, and handling finances [13].
With this provocation, we draw attention to how older adults are represented in $\mathrm{HCl}$ predominantly as individuals experiencing decline in their everyday capabilities and becoming increasingly dependent on assistance from others i.e. as users who require monitoring and assistance. They are rarely depicted as sexual beings although, as Radosh shows in the opening quote (full quote on p3), they actually are. Resisting the trope of ageing as 'slow decay', we problematize discursive depictions of older adults for $\mathrm{HCl}$ research and critique an existing model of care for adults based on Activities of Daily Living (see sidebar), a standardized functional measure used in studies of chronic illness and old aged people. Our goal is to foreground issues that have been otherwise overlooked (e.g. human need for intimacy) and amplify concerns that impede well-being of older adults (e.g. touch deprivation) for future $\mathrm{HCl}$ research.

\section{Writing About Others}

$\mathrm{HCl}$ researchers often write about other people's actions and why those actions matter. Writing about others for $\mathrm{HCl}$ research entails the dual responsibility of faithful representation of an event (in terms of accuracy, detail, clarity, intent, etc) and interpretive cohesion of that event in relation to other events (in terms of narrative, priority, agency, contextual sensitivity, etc). $\mathrm{HCl}$ researchers produce and maintain writing about others as discursive subjectivities that are historically situated and reflexive. How so?

$\mathrm{HCl}$ researchers write about others by producing ethnographic accounts, statistical representations, standardized measures, personas, use case scenarios, design fictions, and research agendas to create specific visions of technology mediated futures. Such writing about others can be used to represent people's needs in product development processes, justify design choices, guide decision making for policies, advocate for consumer rights, and support specific technological possibilities for the future (by extension refrain others). By writing about other people's actions, behaviors, experiences, and bodies, $\mathrm{HCl}$ researchers introduce: (a) text as research knowledge on subjects and, (b) context upon which such knowledge is to be made sense of.

Through the production of text and context on others, $\mathrm{HCl}$ researchers engender and enable specific discursive subjectivities such as users, consumers, participants, hackers, etc in their writings. Such discursive subjectivities are constituted through "the ways in which discursive practice frames individual subjectivities within larger social environment" [1]. Further, production of discursive subjectivities through research writing is contingent on existing paradigms in the field i.e. discursive subjectivities are historically situated and reflexive.

For instance, Bannon outlines the intellectual development of $\mathrm{HCl}$ research over time by tracing various frames of references such as human as information processor, computer as intelligent agent, etc [2]. Bannon articulates how different frames of references enable different agendas and allow different ways of talking about others through research writing. Therefore, how we represent others through our research depends on accepted modes of representation (such as ethnographic accounts, demographic survey, etc) and available frames of references currently practiced in $\mathrm{HCl}$ discourses. Thus, individuals are understood and represented as different discursive subjectivities under different research paradigms. 


\section{Grieving for my sex life after my husband died}

"I rolled over on my side and saw that my husband of almost 40 years was grinning. "It's not supposed to be this good when you're this old." He was right. Our whole generation had been lied to. Holding hands, tender hugs, and a peck on the cheek were supposed to be the acceptable acts for older couples still in love. Anything more intimate than that was either unacknowledged or grist for cartoons and standup comedians - funny at best, but more likely kind of disgusting.

Bart and I never bought into that stereotype. We were septuagenarians now, and the sex was still fun. It bound us together.

...Missing touch didn't have anything to do with sex, I was told, and could be replaced with massages, cuddling grandchildren, and even going to hair salons to get shampoos. Clearly, they didn't know what Bart was like in bed" [16].
Rewriting others as discursive subjectivities

Discursive subjectivities in research writing are both descriptive and prescriptive i.e. they are not merely observed descriptions of people but more importantly act as curated performatives. Performatives foreground the relationship between action and effect, use and change through the idea that "one's identity emerges through various actions performed, and the resulting experiences" [11]. Discursive subjectivities serve as legitimized knowledge about others for further research and practice. Researchers write about others in specific ways (e.g. users, experts, informants, etc) for specific purposes as dictated by their existing disciplinary practices. Grinter eloquently states: "Othering happens when the people who control knowledge production represent those who do not" [7]. In the process of writing about others, $\mathrm{HCl}$ researchers rewrite others as discursive subjectivities for specific purposes.

Here we draw attention to the use of tropes as rhetorical devices in rewriting of others through research. Tropes aid convenient generalizations and lend persuasive force by hinting at what may feel obvious and yet unsaid. In research writing, tropes are pragmatic tools that can be used to evoke and normalize certain narratives over others. Let us look at two examples. First, Irani et al. explore the notion of postcolonial computing and point out colonial tropes that characterize "certain people as in need of enlightenment, civilization, and development" through research agendas in $\mathrm{HCl}$ for technology design [8]. Second, Spiel et al. survey literature on technology for children with autism and argue that existing research reinforces the problematic narrative of "autism as a medical deficit in need of 'correction"' thereby ignoring the needs of neurodiverse individuals [18].

Research narratives emboldened by tropes steer dialog and action in a specific direction with specific goals as the obvi- ous logical next step. Thus, development is the obvious logical next step to perceived under-development and assistive technology becomes the obvious logical next step to help individuals who are cast as deficit discursive subjectivities. Tropes perform a normalizing function in research writing by rendering discursive choices as common sense i.e. obvious and yet unsaid. Rewriting of others through research can be problematic for various reasons even though such issues may not always be immediately apparent or easy to critique. Thus, discursive subjectivities produced as legitimized knowledge about others through writing are normalized (i.e. made as norm) using tropes for further research and practice. Above examples $[8,18]$ demonstrate how tropes operate to normalize certain narratives by supporting problematic assumptions and convenient generalizations leading to marginalization of certain groups of individuals.

\section{Resisting the 'Slow Decay' Trope}

In the quote (see sidebar), Radosh opens up about her lived experience of erotic pleasure and sexual intimacy as a septuagenarian to foreground the often ignored topic of sexual bereavement (mourning the loss of sexual intimacy when predeceased) within grief and geriatric research.

Through a survey study on the issue, Radosh and Simkin argue that "reluctance to acknowledge sexual bereavement may create "disenfranchised grief" leaving the bereaved unsupported in coping with this aspect of mourning" among older adults [17]. Radosh's work highlights how sexuality is inextricably related to various aspects of human life and the perils of ignoring such a fundamental and core aspect of being human. Sexuality and sexual needs of older adults are rarely acknowledged within research literature across disciplines and "there is limited good-quality research into the sex lives of older people" [19]. In other words, it seems that somehow, they are never considered horny! 


\section{Sexual Wellbeing and $\mathrm{HCl}$} There has been a steady increase in $\mathrm{HCl}$ scholarship focusing on various aspects of human sexuality [10, 3]. Recently, the organizers of the 'Design for Sexual Wellbeing in HCl' workshop argue for approaching sexua wellbeing as a fundamental human rights issue and social justice concern while designing technologies [9].

There is a call for future $\mathrm{HCl}$ research "to make visible and counter unjust sexist prac-

tices that are reified through intersecting regimes of oppression such as colonialism ableism, racism, ageism, etc. by designing interventions to improve life quality for all" [9]

\section{Sexuality of Older Adults}

It is crucial to approach human sexuality as evolving

as we age, diverse, and value laden. Future $\mathrm{HCl}$ research on sexuality of older adults should strive to explore various facets including asexuality, celibacy, sexual bereavement, sex after divorce, sexual abuse in care homes, elderly dating, etc.
Older adults as asexual discursive subjectivities Through a discourse analysis of 644 archival papers on ageing related research, Vines et al "argue that in $\mathrm{HC}$ "older users" are often portrayed as people with a set of specific characteristics: they have a range of health concerns, they experience physical and cognitive decline, they are slow at performing with technology, and experience social isolation and a loss of independence" [20]. Carroll et al resist the narrative of deficit driven design wherein "the design intervention orients to and addresses problems, in this case the negatives of growing old alone and isolated, and seeks to mitigate these deficits" by positioning elderly people as organizational firekeepers [4]. Inspired by such efforts to resist deficit driven design that casts older adults into limited stereotypes, we would like to disturb existing asexual portrayals of older adults in $\mathrm{HCl}$ research. The 'slow decay' trope activates narratives of ageing as inevitable decline in capabilities to function and enjoy everyday life. By casting older adults as individuals who require monitoring and assistance because of their decline in capabilities, such narratives can perpetuate negative and harmful stereotypes. The 'slow decay' trope pushes monitoring and assistance as the obvious logical next step to improving lives of older adults instead of building community and au tonomy. Resisting such narratives, we argue for more $\mathrm{HCl}$ research exploring sexual wellbeing of older adults.

\section{Why research the sexuality of older adults?}

Sexuality and sexual needs of older adults are neither acknowledged nor represented within existing $\mathrm{HCl}$ research. ADL has been used to develop and study ambient information systems [6], real-time monitoring [14], smart homes $[12,5]$, and assistive living [21] for older adults, to name a few. Since ADL does not account for sexual needs of older adults, $\mathrm{HCl}$ works built on $\mathrm{ADL}$ perpetuate the same, which we find both worrying and puzzling as researchers. Here we point to three problematic assumptions that impede research concerning sexual well-being of older adults:

Sexual pleasure is not important for older adults Sexual needs and desires of older adults are assumed to either be non-existent or take lower priority compared to other needs i.e. a decline in interest and ability to enjoy sex. This assumption can lead to researchers ignoring serious issues like touch deprivation in older adults.

Sexual desires of older adults are a deviance from norm The sexuality of older adults is often portrayed as comical, embarrassing, odd, and at times perverted (e.g. intergenerational sexual relationships are usually mocked at by implying bodies of older adults cannot be desirable or sexually arousing to others; derogative words include 'cougar' for older women and 'creep' for older men.)

Sexual needs of older adults are homogeneous

Older adults are assumed to all have (or lack) the same sexual needs, challenges, beliefs, and experiences. Further, sexual abuse and frustrations among older adults living in care facilities are seldom discussed while considering the design of such spaces.

In conclusion, $\mathrm{HCl}$ lacks the language, methodologies, and technologies that enable researchers to address sexual needs of older adults. One way of doing this would be to consider sexuality as an indispensable part of human experience while conceptualizing models of care for older population. This would for instance make it easier to show that multimodal research should also be better at understanding how touch communicates feelings and supports intimate visual or speech communication. Most importantly, we must strive to resist harmful tropes while representing the needs, desires, and experiences of older adults through $\mathrm{HCl}$ research. 


\section{References}

[1] Robin Andersen. 1997. Women, Welfare, and the United States Media. In Communication Ethics and Universal Values, Clifford Christians and Michael

Traber (Eds.). SAGE Publications, Inc., 300-326.

[2] Liam J. Bannon. 2017. Elucidating Frames of Reference for $\mathrm{HCl}$. Springer International Publishing, Cham, 5-11. DOI :

http://dx.doi.org/10.1007/978-3-319-56291-9_2

[3] Jeffrey Bardzell and Shaowen Bardzell. 2011.

Pleasure is Your Birthright: Digitally Enabled Designer Sex Toys as a Case of Third-Wave $\mathrm{HCl}$. In

Proceedings of the SIGCHI Conference on Human

Factors in Computing Systems (CHI '11). Association for Computing Machinery, New York, NY, USA, 257-266. DOI :

http://dx.doi.org/10.1145/1978942.1978979

[4] John M. Carroll, Gregorio Convertino, Umer Farooq, and Mary Beth Rosson. 2012. The firekeepers: aging considered as a resource. Universal Access in the Information Society 11, 1 (2012), 7-15. DOI :

http://dx.doi.org/10.1007/s10209-011-0229-9

[5] Anthony Fleury, Michel Vacher, and Norbert Noury. 2010. SVM-Based Multimodal Classification of Activities of Daily Living in Health Smart Homes: Sensors, Algorithms, and First Experimental Results. Trans. Info. Tech. Biomed. 14, 2 (March 2010), 274-283. DOI :

http://dx.doi.org/10.1109/TITB. 2009.2037317

[6] Juan Pablo García-Vázquez and Marcela D. Rodríguez. 2009. Ambient Information Systems to
Support the Elderly in Carrying Out Their Activities of Daily Living. In Proceedings of the Confederated International Workshops and Posters on On the Move to Meaningful Internet Systems: ADI, CAMS, EI2N, ISDE, IWSSA, MONET, OnToContent, ODIS, ORM, OTM Academy, SWWS, SEMELS, Beyond SAWSDL, and COMBEK 2009 (OTM '09). Springer-Verlag,

Berlin, Heidelberg, 779-788. DOI :

http://dx.doi.org/10.1007/978-3-642-05290-3_94

[7] Beki Grinter. 2018. Representing Others: $\mathrm{HCl}$ and Postcolonialism. In Critical Theory and Interaction Design, Jeffrey Bardzell, Shaowen Bardzell, and Mark Blythe (Eds.). The MIT Press, Cambridge,

Massachusetts, 723-736.

[8] Lilly Irani, Janet Vertesi, Paul Dourish, Kavita Philip, and Rebecca E. Grinter. 2010. Postcolonial

Computing: A Lens on Design and Development. In Proceedings of the SIGCHI Conference on Human Factors in Computing Systems (CHI '10). Association for Computing Machinery, New York, NY, USA, 1311-1320. DOI :

http://dx.doi.org/10.1145/1753326.1753522

[9] Gopinaath Kannabiran, Alex A. Ahmed, Matthew Wood, Madeline Balaam, Joshua G. Tanenbaum, Shaowen Bardzell, and Jeffrey Bardzell. 2018. Design for Sexual Wellbeing in $\mathrm{HCl}$. In Extended Abstracts of the $2018 \mathrm{CHI}$ Conference on Human Factors in Computing Systems (CHI EA '18). Association for Computing Machinery, New York, NY, USA, Article Paper W09, 7 pages. DOI : http://dx.doi.org/10.1145/3170427.3170639 
[10] Gopinaath Kannabiran, Jeffrey Bardzell, and Shaowen Bardzell. 2011. How HCl Talks about Sexuality: Discursive Strategies, Blind Spots, and Opportunities for Future Research. In Proceedings of the SIGCHI Conference on Human Factors in Computing Systems (CHI '11). Association for Computing Machinery, New York, NY, USA, 695-704. DOI : http://dx.doi.org/10.1145/1978942.1979043

[11] Gopinaath Kannabiran, Ann Light, and Tuck Leong. 2012. Identity, Performativity, and $\mathrm{HCl}$. In $\mathrm{CHI}$ '12 Extended Abstracts on Human Factors in Computing Systems (CHI EA '12). Association for Computing Machinery, New York, NY, USA, 2763-2766. DOI : http://dx.doi.org/10.1145/2212776.2212715

[12] Minho Kim, Sun-Lee Bang, Sa-Kwang Song, Jaewon Jang, Junho Lim, Seon-Hee Park, and Soo-Jun Park. 2008. A Novel System for Inferring Activities of Daily Living in Smart Home. In Proceedings of the IASTED International Conference on Telehealth/Assistive Technologies (Telehealth/AT '08). ACTA Press, USA, 93-98.

[13] M. Powell Lawton and Elaine M. Brody. 1969. Assessment of Older People: Self-Maintaining and Instrumental Activities of Daily Living1. The Gerontologist 9, 3 (1969), 179-186. DOI : http://dx.doi.org/10.1093/geront/9.3_Part_1.179

[14] Zongfang Lin, Allen R. Hanson, Leon J. Osterweil, and Alexander Wise. 2011. Precise Process Definitions for Activities of Daily Living: A Basis for Real-Time Monitoring and Hazard Detection. In Proceedings of the 3rd Workshop on Software Engineering in Health Care (SEHC '11). Association for Computing Machinery, New York, NY, USA, 13-16. DOI : http://dx.doi.org/10.1145/1987993.1987998

[15] Linda S. Noelker and Richard Browdie. 2013. Sidney Katz, MD: A New Paradigm for Chronic Illness and Long-Term Care. The Gerontologist 54, 1 (08 2013), 13-20. DOI :

http://dx.doi.org/10.1093/geront/gnt086

[16] Alice Radosh. 2018. Grieving for My Sex Life After My Husband Died. (Feb 2018).

https://www. thecut.com/2018/02/

grieving-for-my-sex-life-after-my-husband-died. html

[17] Alice Radosh and Linda Simkin. 2016. Acknowledging sexual bereavement: a path out of disenfranchised grief. Reproductive Health Matters 24, 48 (2016), 25-33. DOI :

http://dx.doi.org/10.1016/j.rhm.2016.11.005 PMID: 28024674

[18] Katta Spiel, Christopher Frauenberger, Os Keyes, and Geraldine Fitzpatrick. 2019. Agency of Autistic

Children in Technology Research-A Critical Literature Review. ACM Trans. Comput.-Hum. Interact. 26, 6, Article Article 38 (Nov. 2019), 40 pages. DOI : http://dx.doi.org/10.1145/3344919

[19] Abi Taylor and Margot A. Gosney. 2011. Sexuality in older age: essential considerations for healthcare professionals. Age and Ageing 40, 5 (07 2011), 538-543. DOI :

http://dx.doi.org/10.1093/ageing/afr049 
[20] John Vines, Gary Pritchard, Peter Wright, Patrick Olivier, and Katie Brittain. 2015. An Age-Old Problem: Examining the Discourses of Ageing in $\mathrm{HCl}$ and Strategies for Future Research. ACM Trans.

Comput.-Hum. Interact. 22, 1, Article Article 2 (Feb. 2015), 27 pages. DOI :

http://dx.doi.org/10.1145/2696867
[21] Shuai Zhang, Sally Mcclean, Bryan Scotney, Xin Hong, Chris Nugent, and Maurice Mulvenna. 2010. An Intervention Mechanism for Assistive Living in Smart Homes. J. Ambient Intell. Smart Environ. 2, 3 (Aug. 2010), 233-252. 